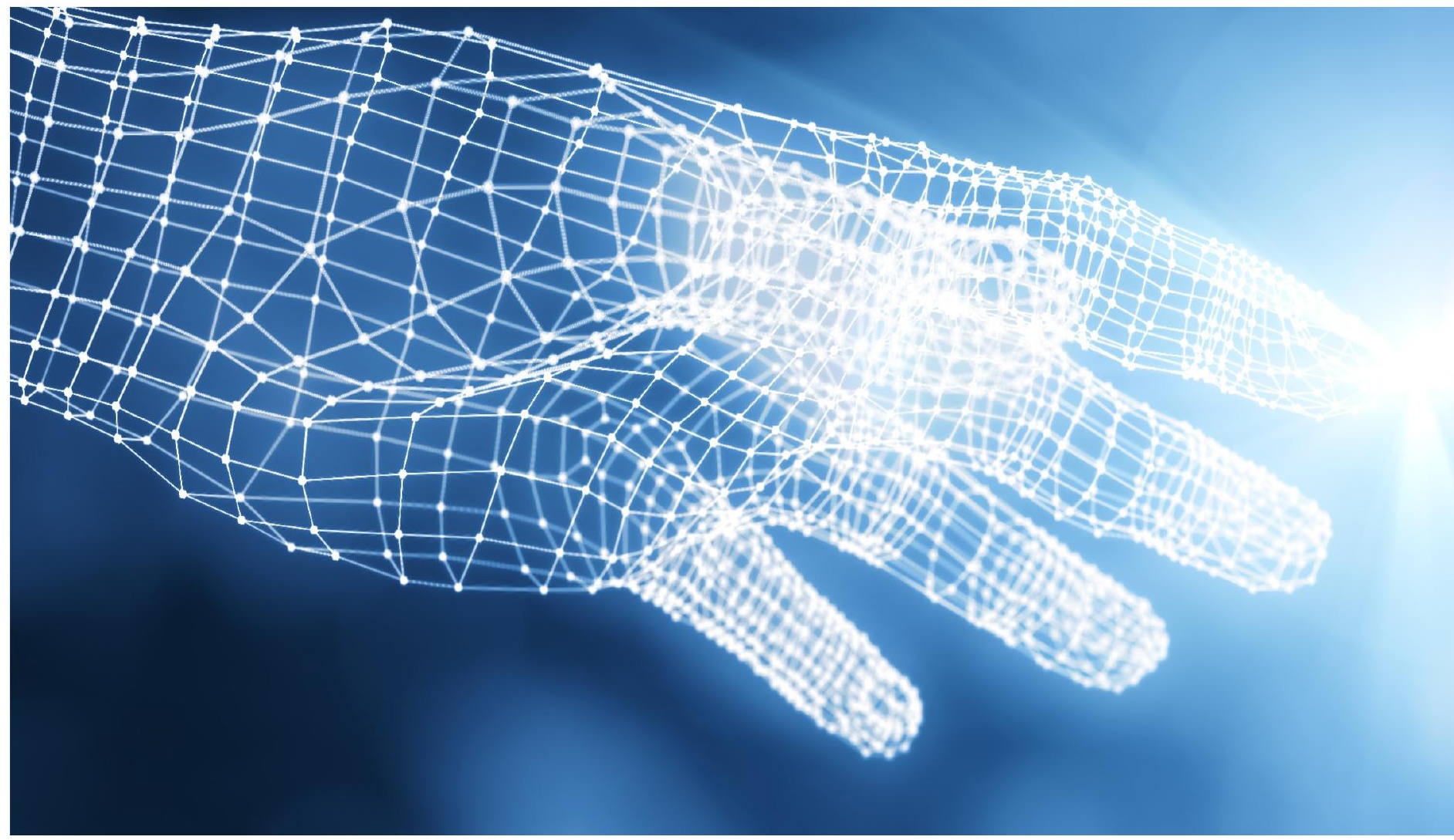

\title{
INÍCIO DE UMA ERA DISRUPTIVA
}

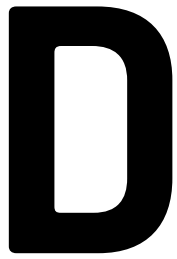

esde os livros de Júlio Verne e Isaac Asimov, passando pelo filme clássico de Stanley Kubrick 2001: Uma Odisseia no Espaço e pelos desenhos de Os Jetsons, temos visões (de bem-estar ou medo) sobre o que o futuro nos reserva com o avanço tecnológico. No entanto, tais tecnologias não estão mais no futuro; elas dirigem o nosso presente. Emblemáticos são os exemplos do software Watson, da IBM, que está modificando completamente a forma de diagnosticar doenças; e das impressoras 3D, já utilizadas na produção de bens por muitas empresas.

Nesta edição especial sobre Tecnologia de Informação (TI), apresentamos artigos que mostram alguns aspectos dessa transformação em empresas públicas e privadas, com impactos que vão além do cotidiano das pessoas e das cidades.

Alberto Luiz Albertin e Rosa Albertin discutem a Internet das Coisas, que permite a integração de dados obtidos por sensores nos objetos. É quase impossível pensar na abrangência que essas conexões permitem. Entre os exemplos, Fabio Faria, diretor de Tecnologia de Informação da Companhia Siderúrgica Nacional (CSN), mostra como sensores em caminhões modificam empresas de mineração, e Luzia Valéria Sarno, da Copersucar, ressalta a importância da automação no agronegócio. Ainda nessa temática, Rodrigo Fernandes Malaquias destaca o impacto da Internet das Coisas na gestão pública, especialmente nas cidades inteligentes, e Cid Torquato, Secretário 


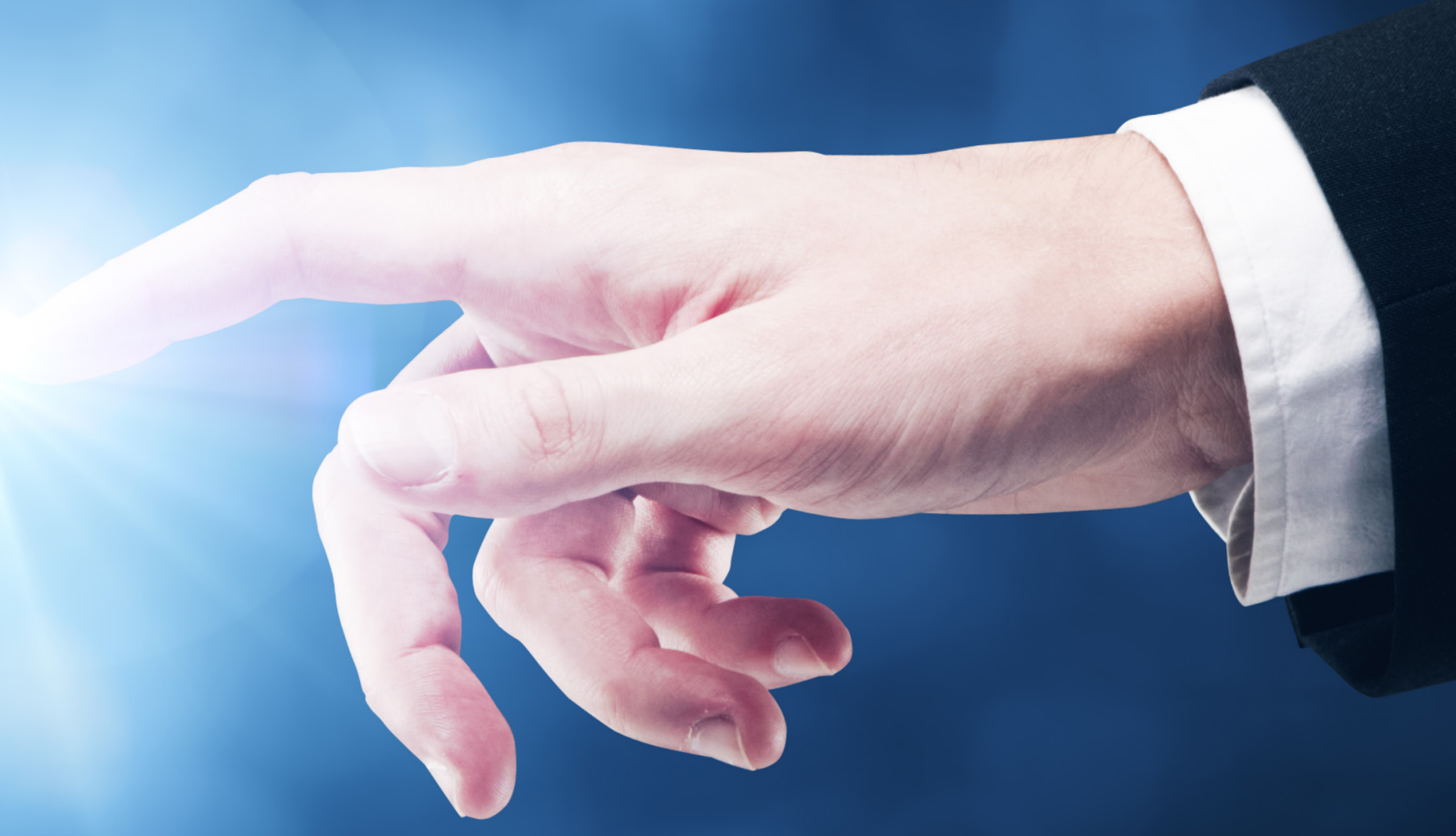

municipal da Prefeitura de São Paulo, enfatiza os benefícios dessa tecnologia para as pessoas com deficiência.

Eduardo Francisco, José Luiz Kugler e Cláudio Larieira argumentam que a transformação digital tem impactos amplos sobre os consumidores, os gestores de TI e a integração entre áreas. Julio Baião salienta que são esperados novos tipos de profissionais nesse contexto, arquitetos capazes de lidar com a profusão de informações. Sergio Lozinsky fala sobre a dificuldade de saber o que estudar nesse cenário de inovação.

Agenor Leão, Vice-presidente de Negócios Digitais da Natura, relata como a empresa criou um novo modelo de negócios baseado nas relações on-line.

Marta de Campos Maia e Italo Flammia debatem como grandes empresas ganham vantagem competitiva ao adotar o crowdsourcing e as incubadoras de empreendimentos.

Como as organizações devem investir em TI? Fernando Meirelles mostra que é preciso desenvolver indicadores para gerar melhores resultados e Jorge Luis Cordenonsi, do Information Services Group (ISG), explica a maneira como as empresas utilizam esses indicadores na prática.

Os artigos finais deste caderno especial tratam do impacto da tecnologia nas finanças. Adrian Kemmer Cernev indica o surgimento de novos meios de pagamento eletrônico que podem contribuir para o desenvolvimento econômico, e Norberto Marque defende que as transações financeiras digitais desafiam o modelo tradicional de bancos. Para concluir, Eduardo Diniz discute como o blockchain, além de revolucionar as finanças, tem grande potencial disruptivo ao também transformar a troca de informações nos negócios. O futuro, com o uso intenso de grandes dados, trará mudanças sociais talvez nunca pensadas. Seremos cyborgs?

Completam a edição as colunas $O$ medo paralisa atitudes e esvazia os bolsos, de Samy Dana; Protecionismo, divida pública e retomada do crescimento, de Paulo Sandroni; Obra de Deus - com foco na onda conservadora de Donald Trump, que deteriora os direitos socioambientais -, de Mario Monzoni; e Novos rumos para a gestão do desempenho, de Beatriz Maria Braga.

Boa leitura!

Maria José Tonelli - Editora chefe

Adriana Wilner - Editora adjunta 